\title{
INFLUENCE OF WATER PRESSURE ON SURFACE ROUGHNESS PARAMETERS IN ABRASIVE WATERJET CUTTING ON AM60 MAGNESIUM ALLOY
}

\author{
S. Spadło*, D. Krajcarz**
}

\begin{abstract}
This paper presents the results of changing the water pressure and its influence on surface roughness parameters in abrasive water jet cutting. The pressure parameter of the water jet has an influence on the overall performance of the abrasive water jet cutting. The as machined surfaces were examined in 3 areas sections at different cutting depths by precision optical measurement system $3 D$ profiler Talysurf CCI Lite. The results show that surface roughness parameters are lower when the water pressure is higher. Another relation is that the smallest values of surface roughness parameters are obtained for profile close to the upper edge cutting surface. On the contrary, the profile close to the bottom edge is characterized by a significant increase of surface roughness with decreasing water pressure. However, at lower water pressure the kinetic energy of the stream of abrasive particles is not sufficient to execute smooth cutting. This phenomenon causes deterioration of the surface quality and in extreme cases, may cause insufficient material removal. Abrasive water jet cutting seems to be promising tool for machining magnesium alloys like AM60.
\end{abstract}

Keywords: abrasive water jet cutting, magnesium alloys, surface roughness

\section{Introduction}

Abrasive Water Jet Cutting (AWJ) is a considered a new method nonconventional material removal technology, which are constantly gaining in importance of manufacturing industry (Ciglar et al., 2009). Exceptional opportunities provided by this process are especially universality of the process, possibility of savings materials, no heat affected zone on workpiece, small feed forces during cutting (Chithirai Pon Selvan et al., 2014). Because of its universality, the method can be used to cut most materials, into any complex shape; hence its wide range of applications (Krajcarz et al., 2017).

Magnesium alloys have ability to maintain high strengths at light weights (Mola et al., 2016). Due to the fact that magnesium is the lightest structural metal has gained widespread use in automotive and electronics industries. When coupled with the advantages of the metal casting process, magnesium alloys allowing for part consolidation and weight savings over other materials and manufacturing methods. The wider use of magnesium alloys remains restricted by inherent limitations like poor formability, including vulnerability to corrosion and low creep resistance (Choong, 2007).

Surface roughness parameters are one of the most important requirements of surface quality in machining of materials (Nowakowski et al., 2017b). However, they play an important role in determining how a made element will interact with cooperating element. In tribology, rough surfaces wear more quickly and have higher friction coefficients than smooth surfaces. The latest studies dealing with AWJ cutting shows that the water pressure has a strong influence on the surface finish (Hlavac et al., 2017). In AWJ cutting surface roughness parameters varies according to the depth of measurement (Begic-Hajdarevic et al., 2015).

\footnotetext{
Assoc. Prof. Sławomir Spadło: Faculty of Mechatronics and Mechanical Engineering, Kielce University of Technology, Street al. Tysiąclecia Państwa Polskiego 7, 25-314, Kielce; PL, sspadlo@tu.kielce.pl

** Daniel Krajcarz, M.Sc.Eng.: Faculty of Mechatronics and Mechanical Engineering, Kielce University of Technology, Street al. Tysiąclecia Państwa Polskiego 7, 25-314, Kielce;PL,dkrajcarz@tu.kielce.pl
} 
The aim of this study was to measure the surface roughness parameters of the machined surface for magnesium alloy AWJ-machined at different water pressure.

\section{Materials and methods}

The experiments were carried out on AM60 magnesium alloy specimens with a thickness of $10 \mathrm{~mm}$ by using an APW 2010BB water jet cutting machine. Magnesium AM60 cast alloy has excellent ductility, superior energy absorbing properties, and good strength and cast ability. The important properties of copper are: tensile strength (225-240 MPa), elastic modulus (45 GPa) and yield strength (130 MPa). AM60 has additions of the following elements: aluminium (5.5-6.5\%), manganese (0.24-0.6\%), Zinc $(0.22 \%)$. Other additives do not exceed $0.1 \%$. The experiment was performed at the Laboratory of Electrical Discharge Machining and Finishing of the Kielce University of Technology. The variable process parameter was water pressure. The tests were performed at three different water pressure: 330 , 290 and $250 \mathrm{MPa}$. The constant process parameters are provided in Table 1.

Tab. 1: Constant process parameters for abrasive waterjet cutting.

\begin{tabular}{cc}
\hline Parameter & Value \\
\hline Traverse speed & $200 \mathrm{~mm} / \mathrm{min}$ \\
\hline Stand-off distance & $2 \mathrm{~mm}$ \\
\hline Water orifice diameter & $0.3 \mathrm{~mm}$ \\
\hline Focusing tube diameter & $1.02 \mathrm{~mm}$ \\
\hline Focusing tube length & $76 \mathrm{~mm}$ \\
\hline Abrasive mass flow rate & $3.8 \mathrm{~g} / \mathrm{min}$ \\
\hline Average grain size & $0.212(80 \mathrm{mesh})$ \\
\hline Abrasive type & Indian garnet
\end{tabular}

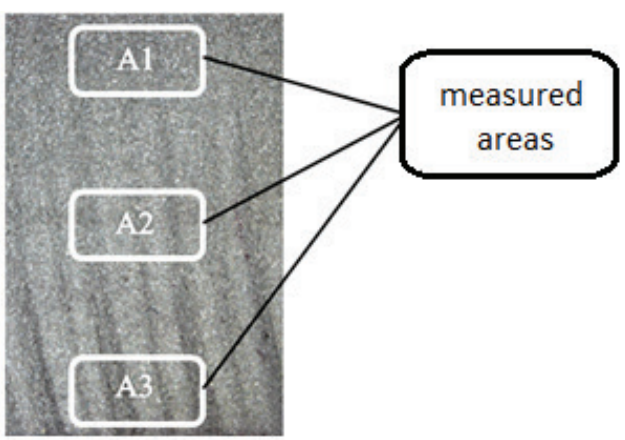

Fig. 1: Measured areas of 3D surface topography (Hlavac et al., 2015).

In the experimental work measurements of the surface were made with the profiler Talysurf CCI - Lite Non-contact 3D Profiler manufactured by Taylor Hobson. All the samples were measured in three different areas as shown in Figure 1. Top (A1 area) and bottom (A3 area) measuring positions were approximately $0.5 \mathrm{~mm}$ from the respective edges. Middle measuring position (A2 area) was measured exactly in the middle of the cutting material. Measurements of the topography at different cutting depths allow to show the influence of a decrease in the kinetic energy of the cutting stream on the quality of the cut of the magnesium alloy. All measured surface topography areas had the same measured window $2.7 \times$ $2.7 \mathrm{~mm}$. The aim was to show the differences in surface roughness topography depending on the areas measurement and various water pressures. Seven parameters of geometric structure are compared $\left(\mathrm{S}_{\mathrm{a}}, \mathrm{S}_{\mathrm{q}}\right.$, $\mathrm{S}_{\mathrm{v}}, \mathrm{S}_{\mathrm{p}}, \mathrm{S}_{\mathrm{z}}, \mathrm{S}_{\mathrm{sk}}, \mathrm{S}_{\mathrm{ku}}$ ) (Spadło et al., 2016). Each area has been thoroughly researched. $\mathrm{S}_{\mathrm{a}}$ 3D parameter expresses the average of the absolute values in the measured area, which is equivalent to the arithmetic mean of the measured region on the three-dimensional display diagram when valleys have been changed to peaks by conversion to absolute values. Parameter $S_{q}$ differs from $S_{a}$ as it expresses the root mean squared in the measured area. The valleys have been changed to high peaks by squaring. $\mathrm{S}_{\mathrm{z}}$ parameter expresses the sum of the maximum value of peak height and the maximum value of valley depth on the surface within the measured area. This is the sum of maximum value of peak heights $S_{p}$ and maximum value of valley depths $S_{v}$ on the surface in the measured area. $S_{\text {sk }}$ and $S_{k u}$ are the skewness and kurtosis of the 3D surface texture respectively. $S_{\mathrm{sk}}$ is useful in d monitoring for different types of wear conditions. $\mathrm{S}_{\mathrm{ku}}$ is useful for indicating the presence of either peak or valley defects which may occur on a surface (Adamczak et al., 2017).

\section{Results and discussion}

The measured characteristics of the surface are summarized in Table 2. The measurements surface examples are presented in Figure 2. The other amplitude parameters $S_{\text {sk }}$ and $S_{k u}$ gave complementary information on the shaping of the geometric structure surfaces. $S_{\mathrm{sk}}$ and $\mathrm{S}_{\mathrm{ku}}$ are sensitive to the local 
hillsides recesses occurring on surfaces. $\mathrm{S}_{\mathrm{sk}}$ parameter generally assumed a negative value which was indicative of the plateau shape of these surfaces. At a lower $S_{\text {sk }}$ value, the surface is more flattened and the tops of the hills are more rounded. The sign of $S_{\text {sk }}$ indicates the small predominance of valley structures $\left(\mathrm{S}_{\mathrm{sk}}<0\right)$ comprising the surface. $\mathrm{S}_{\mathrm{ku}}$ indicates the presence of inordinately high peaks/ deep valleys $\left(S_{k u}>3\right)$ or lack thereof $\left(S_{k u}<3\right)$ making up the texture. If the surface heights are normally distributed then $\mathrm{S}_{\mathrm{sk}}$ is 0.00 and $\mathrm{S}_{\mathrm{ku}}$ is 3 . Surfaces described as gradually varying, free of extreme peaks or valley features, will tend to have $\mathrm{S}_{\mathrm{ku}}<3$. $\mathrm{S}_{\mathrm{ku}}$ parameter revealed that the surface under study characterizes the distribution of ordinates close to the normal distribution in most cases below the value of 3 . It has been noticed that for higher water pressure, the range of variability of the $S_{\mathrm{ku}}$ parameter for different areas of measurements increases and for the pressure of $330 \mathrm{MPa}$ it takes the biggest differences.

Tab. 2: Surface roughness parameters (ISO 25178).

\begin{tabular}{ccccccccccc}
\hline & \multicolumn{9}{c}{ Pressure and area } \\
\cline { 2 - 11 } & \multicolumn{3}{c}{ 250 MPa } & \multicolumn{9}{c}{ 290 MPa } & \multicolumn{3}{c}{ 330 MPa } \\
\cline { 2 - 11 } & $\mathbf{A 1}$ & $\mathbf{A 2}$ & $\mathbf{A 3}$ & $\mathbf{A 1}$ & $\mathbf{A 2}$ & $\mathbf{A 3}$ & $\mathbf{A 1}$ & $\mathbf{A 2}$ & $\mathbf{A 3}$ \\
\hline $\mathrm{S}_{\mathrm{q}}(\mu \mathrm{m})$ & 10.49 & 15.42 & 21.77 & 9.26 & 15.13 & 19.45 & 7.98 & 14.26 & 17.11 \\
\hline $\mathrm{S}_{\mathrm{sk}}(-)$ & -1.04 & 0.12 & -0.36 & -0.15 & -0.43 & -0.09 & -0.25 & -0.14 & -0.04 \\
\hline $\mathrm{S}_{\mathrm{ku}}(-)$ & 2.81 & 2.22 & 2.50 & 2.89 & 2.84 & 2.44 & 3.29 & 2.43 & 1.90 \\
\hline $\mathrm{S}_{\mathrm{p}}(\mu \mathrm{m})$ & 31.28 & 40.14 & 61.56 & 30.72 & 43.87 & 52.49 & 30.34 & 36.85 & 51.74 \\
\hline $\mathrm{S}_{\mathrm{v}}(\mu \mathrm{m})$ & 44.69 & 62.55 & 64.58 & 41.22 & 55.29 & 69.92 & 38.58 & 49.00 & 55.88 \\
\hline $\mathrm{S}_{\mathrm{z}}(\mu \mathrm{m})$ & 75.98 & 102.69 & 126.13 & 71.93 & 99.16 & 122.41 & 68.92 & 85.85 & 107.62 \\
\hline $\mathrm{S}_{\mathrm{a}}(\mu \mathrm{m})$ & 11.27 & 12.79 & 18.24 & 7.34 & 12.70 & 16.76 & 6.31 & 11.50 & 13.90 \\
\hline & & & & & & & & & \\
\hline
\end{tabular}

The comparison parameters $\mathrm{S}_{\mathrm{a}}$ and $\mathrm{S}_{\mathrm{q}}$ for each measuring area and conditions shows increase of each one parameter with both the water pressure and depth of jet penetration into material. An exemplary image of the analyzed surface is shown in the Fig.2. The quality of surface can be determined from the height parameters like $S_{z}, S_{v}$ and $S_{p}$. If the values are higher the quality is worse, because differences between peaks and valleys are increasing. It can be observed that in lower parts of the cut walls the dispersion of measured higher parameter increases. Regardless of the value of the tested water pressure, the deterioration of the amplitude parameters was similar. The measurement area significantly influenced the measurement result. A slightly higher value is assumed by the parameter $S_{v}$ in relation to $\mathrm{Sp}$, which means that the machined surface has rounded peaks with relatively deep depressions.

a)

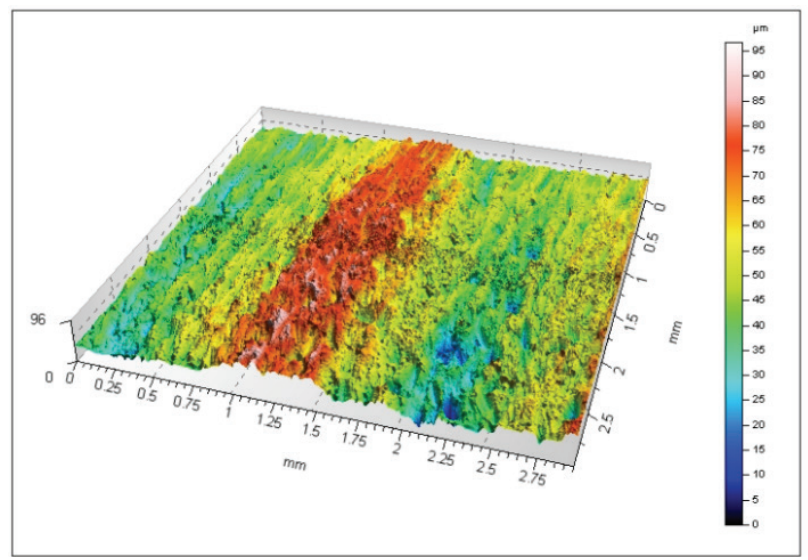

b)

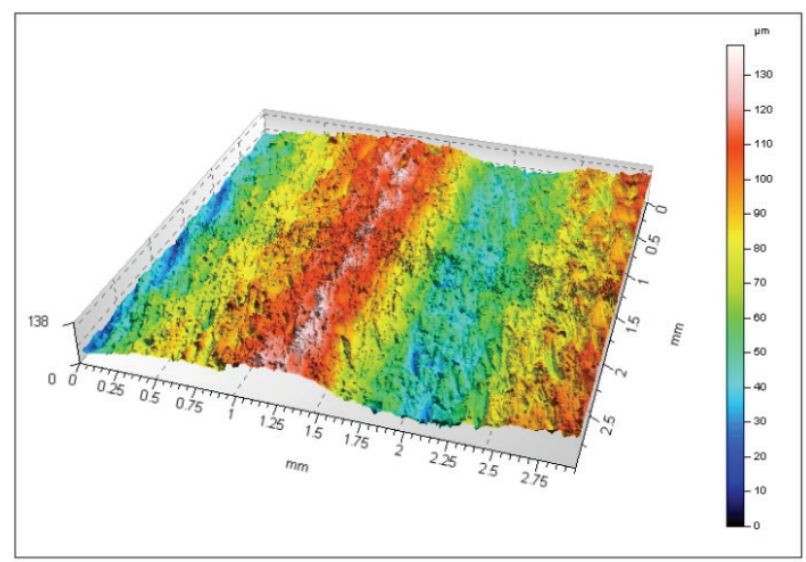

Fig. 2: 3D surface topographyfor water pressure $290 \mathrm{MPa}$ : a) area A1, b) area A3. 


\section{Conclusions}

Tests with the optical profiler Talysurf CCI allowed to conduct an assessment surface quality of the water jet cutting process of AM60 magnesium alloy after machining. Abrasive water jet cutting seems to be promising tool for machining magnesium alloys like AM60.

One of the significant factors that determine the surface quality are surface roughness parameters. The comparison shows increase of each one surface parameter with depth of jet penetration into material. Reducing the water pressure also causes deterioration of the cut surface. The profiles close to the bottom edge are characterized by a lower surface quality with decreasing water pressure. With increase in jet pressure, brittle abrasives break down into smaller ones. Therefore, the water pressure increases, surface becomes smoother. At lower water pressure the kinetic energy of the stream of abrasive particles is not sufficient to execute smooth cutting.

The $\mathrm{S}_{\text {sk }}$ parameter generally assumed a negative value which was indicative of the plateau shape of these surfaces (the small predominance of valley structures). The $S_{\mathrm{ku}}$ parameter ratio ranged between 2 and 3 depending on the measured area, what revealed that the surface under study characterizes the distribution of ordinates close to the normal distribution.

As a result of the analysis, a significantly greater difference in the value of the parameters was found depending on the area of measurement (depth of cut) than in relation to the tested pressure difference.

The research and scientific aim of the conducted work is to choose parameters which will help in the future to avoid cutting surfaces with too low parameters. These are preliminary studies for the future modeling of surface quality of magnesium alloys by using AWJ cutting.

\section{References}

Adamczak, S., Zmarzly, P., Kozior, T. and Gogolewski, D. (2017) Assessment of Roundness and Waviness Deviations of Elements Produced by Selective Laser Sintering Technology, In: Engineering Mechanics 2017, Brno University of Technology, Brno, pp. 70-73.

Begic-Hajdarevic, B., Cekic A., Mehmedovic, M. and Djelmic, A. (2015) Experimental Study on Surface Roughness in Abrasive Water Jet Cutting, 25th DAAAM International Symposium on Intelligent Manufacturing and Automation, Procedia Engineering, vol. 100, pp. 396-399.

ChithiraiPonSelvan, M. and Senthil Kumar, K. (2014) Influence of Process Parameters on Surface Roughness in Abrasive Waterjet Cutting of Titanium, Global Journal of Advanced Engineering Technologies, vol.3, pp. 38-42.

Choong, D. L. (2007) Dependence of tensile properties of AM60 magnesium alloy on microporosity and grain size, Materials Science and Engineering: A, vol. 454-455, pp. 575-580.

Ciglar, D., Udiljak, T., Skoric, S. and Staroveski T. (2009) Influence of abrasive flow rate on surface quality in abrasive water jet cutting. 13th International Research/Expert Conference "Trends in the Development of Machinery and Associated Technology” TMT, Hammamet, Tunisia, pp. 793-796.

Hlavac, L. M., Krajcarz, D., Hlavacova, I. M. and Spadło, S. (2017) Precision comparison of analytical and statistical-regression models for AWJ cutting. Precision Engineering-Journal of the International Societies for Precision Engineering and Nanotechnology, vol. 50, pp. 148-159. DOI: 10.1016/j.precisioneng.2017.05.002

Krajcarz, D., Bańkowski, D. and Młynarczyk, P. (2017) The effect of traverse speed on kerf width in AWJ cutting of ceramic tiles. 12th International Scientific Conference of Young Scientists on Sustainable, Modern and Safe Transport. Procedia Engineering, volume: 192, pp. 469-473.

Mola, R., Bucki, T. and Dziadoń, A. (2016) Formation of Al-alloyed Layer on Magnesium with Use of Casting Techniques. Archives of Foundry Engineering, vol. 16(1), pp. 112-116.

Nowakowski, L., Skrzyniarz, M. and Miko, E. (2017) The assessment of the impact of the installation of cutting plates in the body of the cutter on the size of generated vibrations and the geometrical structure of the surface, In: Engineering Mechanics 2017, Brno University of Technology, Brno, pp. 734-737.

Spadło, S. and Młynarczyk, P. (2016) Analysis of the mechanical interactions of the filament brush electrode on the formation of the surface roughness, in: Proc. 25th Int. Conf. Metall. Mater. Met. 2016 pp: 1169-1174. 